\title{
Rare cause for base of the thumb pain: $A$ vascular necrosis of Paratrapezium Bone, case report
}

\author{
Ahmed Shawgi Hagnasir M. D, Gazwan Maki M.D \\ UAE
}

Correspondence: Ahmed Shawgi Hagnasir, United Arab Emirates, Email Ahmed.Hagnasir@Mediclinic.ae

Received: May 15, 2018 | Published: June 05, 2018

Copyright@ 2018 Hagnasir et al. This is an open access article distributed under the terms of the Creative Commons Attribution License, which permits unrestricted use, distribution, and reproduction in any medium, provided the original author and source are credited.

\begin{abstract}
Background: Anatomical variations of the trapezium are rare. Even more a vascular necrosis (AVN) of the trapezium is uncommon, as it's a well vascularized bone. In this article, the author describes a case of unilateral idiopathic AVN of the para trapezium bone, which is a rare cause can be added to the list of base of the thumb pain. According to our knowledge this is the first case reported in the literature.

Case: A 31 years old right-handed Asian lady from Middle East, used to work an office job- mainly typing for the past 4 years. The patient presented with severe right wrist pain, which started gradually and increased over 6 days. The pain was unresponsive to NSAIDs and paracetamol. The pain was localized on the radial side of the wrist at the base of the thumb. There was no history of trauma or fever. No similar condition in the past, and the left hand was free of symptoms. The patient is non-smoker, non-alcoholic. She has no medical illness or steroid use in the past.
\end{abstract}

On physical examination, the thumb was kept in adduction position. There was slight prominence at the base of the right thumb, with mild swelling and erythema. The area was tender with limited range of movement especially on abduction and extension.

The patient was seen in ER and the symptoms diagnosed as cellulitis.

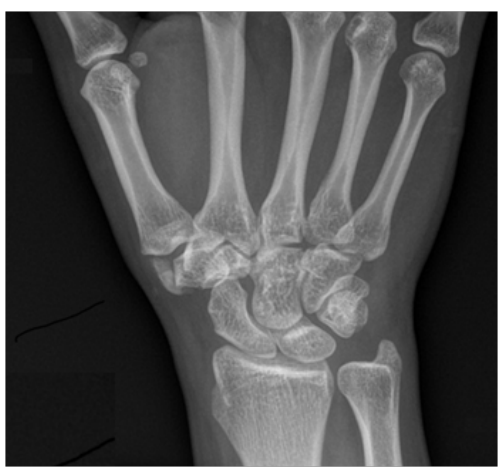

The initial laboratory results showed normal WBC, ESR, rheumatoid factor, Serum uric acid and creatinine with slightly elevated CRP.

X-ray showed accessory bone on the radial side of the trapezium measuring about $1 \mathrm{~cm}$ longitudinally, which is partially articulating with the first metacarpal bone, showing sclerotic changes, Figure 1, which is consistent with paratrapezium. X-ray of the left wrist was unremarkable.

MRI of right hand with gadolinium enhancement demonstrates a vascular necrosis of paratrapezium Figure 2. On the STIR and T1 weighted series no bone marrow signal was seen, with neither no enhancement on the post gadolinium series.

The patient received i.v antibiotics and pain management for 48 hours, which showed no response. Local intra-articular corticosteroid injection in the first carpometacarpal joint relieved the pain, and the patient was discharged with a thumb splint. She was planned for excision of the paratrapezium.

Six weeks later the Necrotic paratrapezium was excised completely. Follow up at 6 weeks, 3 months and 1 year showed full recovery from pain with good movement around the wrist and carpo-metacarpal joints.

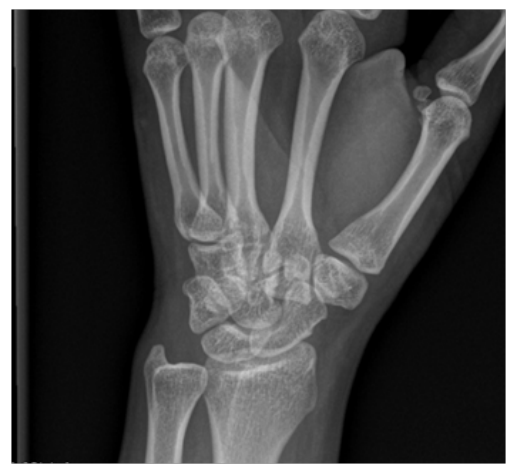

Figure I

(Ia) X-ray of the right hand shows the paratrapezium measuring around $10 \mathrm{~mm}$ longitudinal, which is partially articulating with the first metacarpal bone. Sclerosis of the paratrapeium is shown

(Ib) shows normal trapezium articulating with the first metacarpal bone of left hand. 

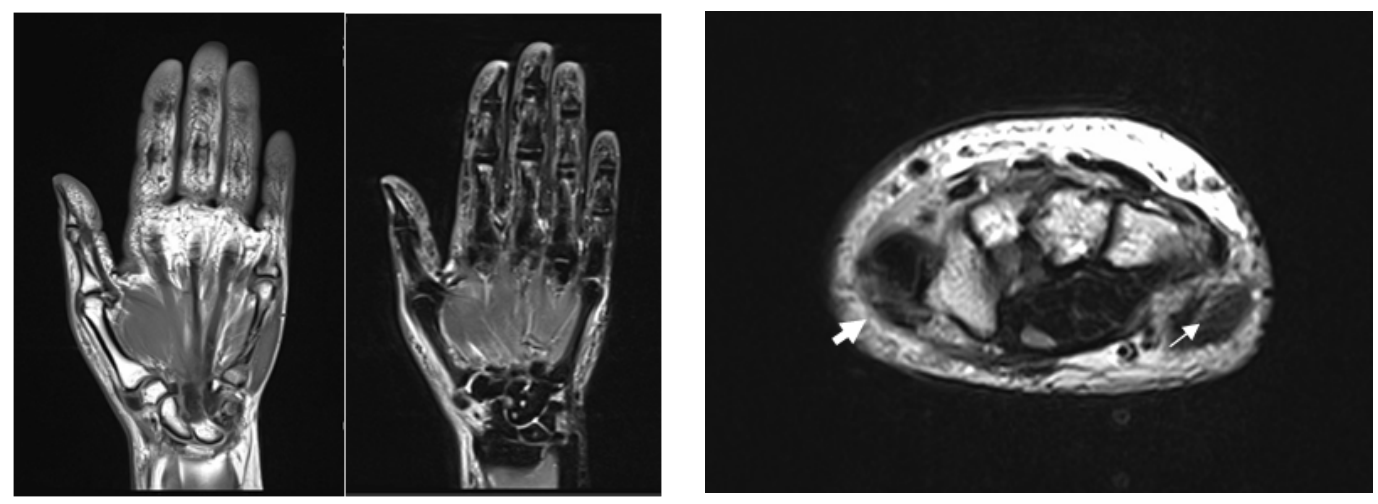

Figure 2 MRI with gadolinium enhancement of right hand. Left is coronal TI weighted image shows large accessory bone of I cm (paratrapezium) articulating with the trapezium and also with the base of the first metacarpal (white arrow). Middle is STIR image and right is Axial T2 weighted image show accessory bone which is completely dark with no bone marrow signal, showing no enhancement post Gadolinium (small white arrows). The findings are consistent with a vascular necrosis of the paratrapezium.

\section{Discussion}

Congenital abnormalities of the trapezium are uncommon. Pfitzner (1895) stated that, during embryological life, the trapezium consists of a main center, and four minor cartilaginous centers ${ }^{1}$. Which may persist as separate bones in adult life Figure 3. The epitrapezium is next to the scaphoid on the dorsal aspect; the paratrapezium at the outer angle which articulates with the first metacarpaal bone; the secondary trapezium at the distal angle between the first and second metacarpals; and the praetrapezium is at the distal end of the tuberosity on the palmar surface.

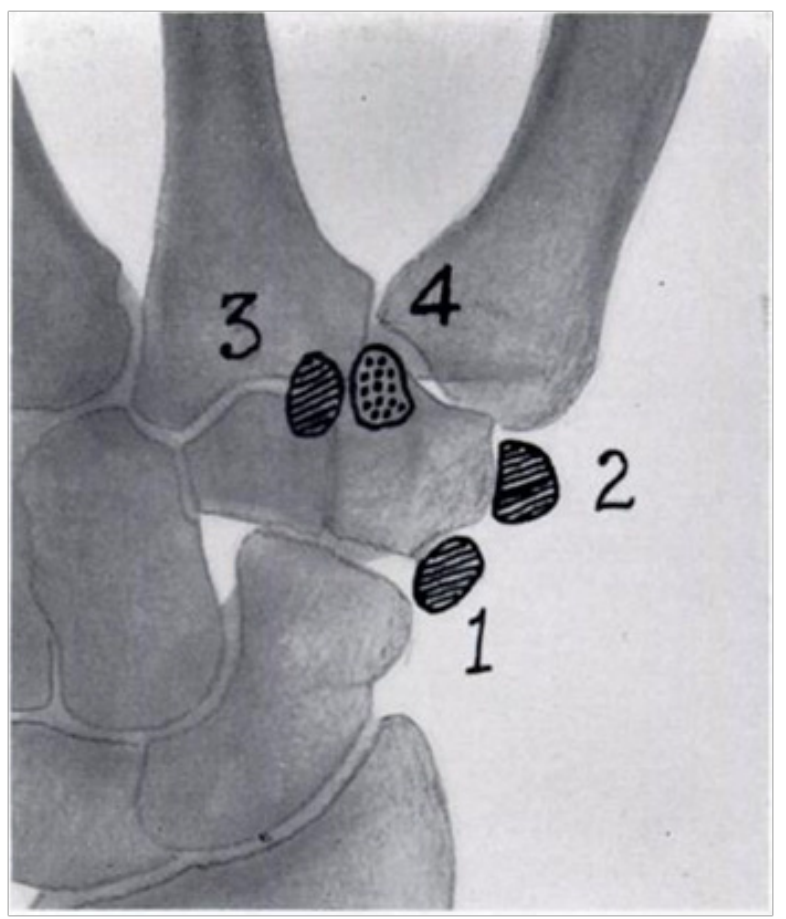

Figure $3 \mathrm{~A}$ diagram of the accessory centers of the trapezium from the dorsal aspect; (I) the epitrapezium, (2) the paratrapezium, (3) the secondary trapezium, the praetrapezium (4) is on the palmar aspect.
It seems that the eldest reported case for paratrapezium was demonstrated as an ossicle articulating with the first metacarpal in Cuyer's drawing (1887). ${ }^{2}$

Dwight (1907) in a monograph on accessory bones stated that he had seen the praetrapezium in a pair of hands and that the epitrapezium had been reported once. He had not seen a paratrapezium but had found a secondary trapezium as a distinct bone once ${ }^{1}$. Grumbach (1921) reviewed Pfltzner's plan and he ascribed most of these accessory bones to injury, with the possible exception of the epitrapezium. ${ }^{3}$

Heimerzheim (1925) mentioned a case similar to Cuyer's. ${ }^{4}$ And Rushforth (1949) reported a case of a 65 years lady presented with bilateral deformity of base of each thumb with limited range of movements, radiographs showed paratrapezium on one hand and praetrapezium on the other hand. ${ }^{1}$ Steinberg (1978) reported a case of a 12 years-old girl presented with right hand deformity. Abduction and extension was limited compared to the other side. Radiographs showed unilateral bipartite trapezium, the lateral one articulates with the metacarpal bone, and the medial one articulates with the scaphoid and trapezoid.

Blood supply to the wrist is obtained through the radial, ulnar and the anterior interosseous arteries and the deep palmar arch. Apart from the extraosseous arterial pattern, the intrinsic blood supply to the carpal bone is an important factor in the incidence of AVN. It is observed that blood supply to most carpal bones enters the distal half, leaving the proximal half at risk, ${ }^{6}$ however the trapezium receives nutrient arteries through two non-articular surfaces, and has numerous intraosseous anastomoses, ${ }^{7}$ which make AVN of the trapezium bone a rare condition.

AVN of the scaphoid and lunate has been described more than a century ago by Preiser ${ }^{8}$ and Kienbock. ${ }^{9}$ García-López (2002) reported a case of 26-year-old woman presented with radiologic signs of a vascular necrosis of the trapezium bone, he stated a good result after bone excision and suspension arthroplasty. ${ }^{10}$ Zafra (2004) performed a vascularized distal radius bone graft ina20-year-old man presented with early stage osteonecrosis of the trapezium, diagnosed by MRI, He reported good clinical and radiologic results over a 1-year followup period. ${ }^{11}$
Submit your Article | www.ologypress.com/submit-article

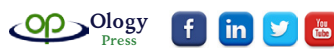

Citation: Hagnasir AS, Maki G. Rare cause for base of the thumb pain:A vascular necrosis of Paratrapezium Bone, case report. Orthopedics Traumatology Spor Med Int J. (20 I8); I: I3-I5. DOI: I0.3088 I/otsmij.00004 


\section{Conclusion}

In this article, paratrapezium bone is documented as an abnormal ossification of the trapezium, which is associated with idiopathic AVN in this case. There is no obvious cause for a vascular necrosis, however it may be attributed to disruption of soft tissue connection and blood supply from the trapezium due to repetitive micro-trauma.

\section{Acknowledgment}

The author would like to thank Mrs. A . M for permission to publish this case.

\section{References}

1. Rushforth AF. A congenital abnormality of the trapezium and first metacarpal bone. J Bone Joint Surg, 1949;Br 31B(4):543-546.

2. Cuyer E. Sur un os surnuméraire du carpe. Bull la Société d'anthropologie Paris [Internet]. Persée - Portail des revues scientifiques en SHS; 1887;10(1):303-306.

3. Grumbach A. Das Handskelett im Lichte der Röntgenstrahlen. Wilhelm Braumüller; Wien,Leipzig. 1921.
4. Heimerzheim A. Über einige akzessorische Handwurzelknochen nebst ihrer chirurgischen Bedeutung. Dtsch Zeitschrift für Chir. 1925;190(12):88-96.

5. Steinberg GG. Bipartite trapezium with adduction contracture of the thumb: a case report. Clin Orthop Relat Res. 1979;145:199-201.

6. Charles A Rockwood, Robert W Bucholz, Charles M Court-Brown, et al. Rockwood and Green's Fractures in Adults. 2010:1.

7. Gelberman RH, Gross MS. The vascularity of the wrist. Identification of arterial patterns at risk. Clin Orthop Relat Res. 1986;20:40-49.

8. Kallen AM, Strackee SD. On the history and definition of Preiser's disease. J Hand Surg Eur Vol. 2014;39(7):770-776.

9. Schmitt R, Heinze A, Fellner F, et al. Imaging and staging of a vascular osteonecroses at the wrist and hand. Eur J Radiol. 1997;25(2):92-103.

10. García-López A, Cardoso Z, Ortega L. Avascular necrosis of trapezium bone: A case report. J Hand Surg Am. 2002;27(4):704-706.

11. Zafra M, Carpintero P, Cansino D. Osteonecrosis of the trapezium treated with a vascularized distal radius bone graft. J Hand Surg Am. 2004;29(6):1098-1101. 